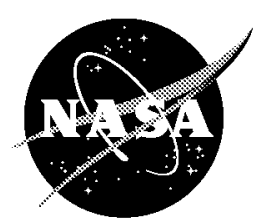

\title{
A Particle and Energy Balance Model of the Orificed Hollow Cathode
}

Matthew T. Domonkos

Glenn Research Center, Cleveland, Ohio 
Since its founding, NASA has been dedicated to the advancement of aeronautics and space science. The NASA Scientific and Technical Information (STI) Program Office plays a key part in helping NASA maintain this important role.

The NASA STI Program Office is operated by Langley Research Center, the Lead Center for NASA's scientific and technical information. The NASA STI Program Office provides access to the NASA STI Database, the largest collection of aeronautical and space science STI in the world. The Program Office is also NASA's institutional mechanism for disseminating the results of its research and development activities. These results are published by NASA in the NASA STI Report Series, which includes the following report types:

- TECHNICAL PUBLICATION. Reports of completed research or a major significant phase of research that present the results of NASA programs and include extensive data or theoretical analysis. Includes compilations of significant scientific and technical data and information deemed to be of continuing reference value. NASA's counterpart of peerreviewed formal professional papers but has less stringent limitations on manuscript length and extent of graphic presentations.

- TECHNICAL MEMORANDUM. Scientific and technical findings that are preliminary or of specialized interest, e.g., quick release reports, working papers, and bibliographies that contain minimal annotation. Does not contain extensive analysis.

- CONTRACTOR REPORT. Scientific and technical findings by NASA-sponsored contractors and grantees.
- CONFERENCE PUBLICATION. Collected papers from scientific and technical conferences, symposia, seminars, or other meetings sponsored or cosponsored by NASA.

- SPECIAL PUBLICATION. Scientific, technical, or historical information from NASA programs, projects, and missions, often concerned with subjects having substantial public interest.

- TECHNICAL TRANSLATION. Englishlanguage translations of foreign scientific and technical material pertinent to NASA's mission.

Specialized services that complement the STI Program Office's diverse offerings include creating custom thesauri, building customized databases, organizing and publishing research results ... even providing videos.

For more information about the NASA STI Program Office, see the following:

- Access the NASA STI Program Home Page at http://wwzo.sti.nasa.gov

- E-mail your question via the Internet to help@stinasa.gov

- Fax your question to the NASA Access Help Desk at 301-621-0134

- Telephone the NASA Access Help Desk at 301-621-0390

- Write to: NASA Access Help Desk NASA Center for AeroSpace Information 7121 Standard Drive Hanover, MD 21076 


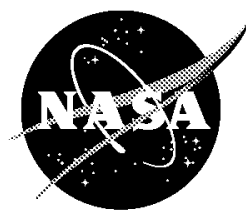

\section{A Particle and Energy Balance Model of the Orificed Hollow Cathode}

Matthew T. Domonkos

Glenn Research Center, Cleveland, Ohio

Prepared for the

38 th Joint Propulsion Conference and Exhibit

cosponsored by the AIAA, ASME, SAE, and ASEE

Indianapolis, Indiana, July 7-10, 2002

National Aeronautics and

Space Administration

Glenn Research Center 
Available from

NASA Center for Aerospace Information 7121 Standard Drive

Hanover, MD 21076
National Technical Information Service 5285 Port Royal Road Springfield, VA 22100

Available electronically at http://glrs.grcnasa.gov 


\title{
A Particle and Energy Balance Model of the Orificed Hollow Cathode
}

\author{
Matthew T. Domonkos \\ National Aeronautics and Space Administration \\ Glenn Research Center \\ Cleveland, Ohio 44135
}

\begin{abstract}
A particle and energy balance model of orificed hollow cathodes was developed to assist in cathode design. The model presented here is an ensemble of original work by the author and previous work by others. The processes in the orifice region are considered to be one of the primary drivers in determining cathode performance, since the current density was greatest in this volume (up to $1.6 \times 10^{8} \mathrm{~A} / \mathrm{m}^{2}$ ). The orifice model contains comparatively few free parameters, and its results are used to bound the free parameters for the insert model. Next, the insert region model is presented. The sensitivity of the results to the free parameters is assessed, and variation of the free parameters in the orifice dominates the calculated power consumption and plasma properties. The model predictions are compared to data from a low-current orificed hollow cathode. The predicted power consumption exceeds the experimental results. Estimates of the plasma properties in the insert region overlap Langmuir probe data, and the predicted orifice plasma suggests the presence of one or more double layers. Finally, the model is used to examine the operation of higher current cathodes.
\end{abstract}

\section{Nomenclature}

\begin{tabular}{|c|c|c|c|}
\hline$\Lambda_{\text {eff }}$ & Effective emission area on the insert $\left(\mathrm{m}^{2}\right)$ & $\ln \Lambda$ & Coulomb logarithm \\
\hline$A_{0}$ & Orifice area, $\mathrm{m}^{2}$ & $\mathrm{~L}_{\mathrm{eff}}$ & Effective emission length from the insert (m) \\
\hline$A_{R}$ & Richardson coefficient $\left(60 \mathrm{~A} / \mathrm{cm}^{2}-\mathrm{K}^{2}\right)$ & $\mathrm{m}_{\mathrm{e}}$ & Electron mass $\left(9.11 \times 10^{-31} \mathrm{~kg}\right)$ \\
\hline $\mathrm{d}_{\mathrm{i}, \mathrm{i}}$ & Inner diameter of the cathode insert ( $\mathrm{mm}$ ) & $m_{i}$ & Ion mass $\left(2.19 \times 10^{-25} \mathrm{~kg}\right.$ for xenon) \\
\hline $\mathrm{d}_{\mathrm{o}}$ & Orifice diameter ( $m$ unless otherwise noted) & $\dot{m}$ & Mass flow-rate $(\mathrm{mg} / \mathrm{s}$ or $\mathrm{sccm})(1 \mathrm{sccm}=$ \\
\hline $\mathrm{e}$ & Electron charge $\left(1.6 \times 10^{-19} \mathrm{C}\right)$ & & $0.097 \mathrm{mg} / \mathrm{s})$ \\
\hline $\mathrm{E}$ & Electron energy $(\mathrm{eV})$ & $\mathrm{M}_{\mathrm{e}}$ & Atomic mass of an electron $(1 / 1836)$ \\
\hline $\mathrm{E}_{\mathrm{ds}}$ & Electric field in the double sheath adjacent to & $\mathrm{M}_{\mathrm{i}}$ & Atomic mass of an ion (131 for xenon) \\
\hline $\mathrm{E}_{\mathrm{Y}}{ }$ & the insert $(\mathrm{V} / \mathrm{m})$ & $\mathrm{M}_{\mathrm{o}}$ & Atomic mass of a neutral (131 for xenon) \\
\hline $\mathrm{E}_{\mathrm{x}}+\mathrm{C}_{2}$ & Axial elec & $\mathrm{n}_{\mathrm{x}}$ & Number density of species $\mathrm{x}\left(\mathrm{cm}^{-3}\right.$ or $\left.\mathrm{m}^{-3}\right)$ \\
\hline$f_{e x}$ & $\begin{array}{l}\text { Escape fraction of emitted electrons } \\
\text { Fraction of excitations causing ionization }\end{array}$ & $\mathrm{N}_{\mathrm{eo}}$ & Number density-rate of electron impact \\
\hline $\mathrm{I}_{\mathrm{D}}$ & Cathode discharge current $(\mathrm{A})$ & $\mathrm{q}_{\mathrm{co}}+2+2,+2$ & Convective power loss (W) \\
\hline $\mathrm{I}_{\mathrm{e}}$ & Electron current to the Langmuir probe (A) & $\mathrm{q}_{\mathrm{e}, \text { back }}$ & Convective power loss due to backstreaming \\
\hline$I_{e, \text { ins }}$ & Electron current from the insert region to the & & electrons $(\mathrm{W})$ \\
\hline e,or & $\begin{array}{l}\text { orifice reg1on (A) } \\
\text { Electron current emitted from the orifice (A) }\end{array}$ & $\mathrm{q}_{\mathrm{e}, \mathrm{con}}$ & $\begin{array}{l}\text { Convective power loss due to electron current } \\
\text { (W) }\end{array}$ \\
\hline $\mathrm{I}_{\mathrm{i}}$ & Bohm ion current at sheath boundary $(\mathrm{A})$ & $\mathrm{q}_{\mathrm{e}, \text { th }}$ & power input \\
\hline $\mathrm{I}_{\mathrm{i}, \mathrm{emit}}$ & Emitted ion current from the orifice $(A)$ & & electrons (W) \\
\hline $\mathrm{I}_{\mathrm{i}, \text { ori }}$ & $\begin{array}{l}\text { Orifice ion current }(\mathrm{A}) \\
\text { Current density }\left(\mathrm{A} / \mathrm{m}^{2}\right)\end{array}$ & $q_{e x}$ & Power loss due to radiation of excited states \\
\hline je,back & Plasma electron backstreaming flux $\left(\# / \mathrm{m}^{2}\right)$ & & Convective power loss due to ion loss (W) \\
\hline$j_{e, t h n n}$ & Thermionic electron current density $\left(\mathrm{A} / \mathrm{m}^{2}\right)$ & $\mathrm{q}_{\mathrm{i} \text { ori }}+\mathrm{C}_{2}$ & Convective power input by orifice ions (W) \\
\hline & Ion flux, $\left(\# / \mathrm{m}^{2}\right)$ & $\mathrm{q}_{\mathrm{ion}}$ & Ionization power loss (W) \\
\hline & Bohm ion current density at sheath boundary & qohmic & ohmic heat generation (W) \\
\hline & $\begin{array}{l}\left(\mathrm{A} / \mathrm{m}^{-}\right) \\
\text {Boltzmann constant }\left(138 \times 10^{-23} \mathrm{~J}\right.\end{array}$ & $r_{0}$ & Orifice radius $(\mathrm{m})$ \\
\hline & & $\mathrm{R}$ & Resistance (Ohms) \\
\hline & Uritice length (mm) & $\mathrm{R}_{\mathrm{sp}}$ & Specific gas constant $(63.1 \mathrm{~J}$ \\
\hline
\end{tabular}




\begin{tabular}{|c|c|}
\hline $\mathrm{U}_{\mathrm{ex}}$ & Average excitation energy $(\mathrm{eV})$ \\
\hline $\mathrm{v}_{\mathrm{e}}, \bar{v}_{e}$ & Electron thermal speed $(\mathrm{m} / \mathrm{s})$ \\
\hline $\bar{v}_{i}$ & Average ion speed $(\mathrm{m} / \mathrm{s})$ \\
\hline $\mathrm{V}_{\mathrm{ds}}$ & Voltage across a planar double sheath (V) \\
\hline $\mathrm{V}_{\mathrm{p}}$ & Plasma potential (V) \\
\hline$\varepsilon_{0}$ & Permittivity of free space $\left(8.85 \times 10^{-12} \mathrm{~F} / \mathrm{m}\right)$ \\
\hline$\phi_{\text {eff }}$ & Effective work function (eV) \\
\hline$\phi_{i}$ & Ionization potential (12.12 eV for xenon) \\
\hline$\phi_{0}$ & Material work function (eV) \\
\hline$\gamma$ & Ratio of specific heats ( $5 / 3$ for xenon) \\
\hline$\eta$ & Plasma resistivity $(\Omega-m)$ \\
\hline$\lambda$ & Wavelength of pyrometer optics (m) \\
\hline$\lambda_{\mathrm{D}}$ & Debye length (cm or m) \\
\hline$\lambda_{\mathrm{ee}}$ & Electron mean free path for self-collision (m) \\
\hline$\lambda_{\mathrm{ex}}$ & Electron mean free path for excitation (m) \\
\hline$\lambda_{\text {ion }}$ & Electron mean free path for ionization (m) \\
\hline$\mu$ & Permeability $(\mathrm{H} / \mathrm{m})$ \\
\hline$\mu_{\mathrm{o}}$ & Permeability of free space $\left(4 \pi \times 10^{-7} \mathrm{H} / \mathrm{m}\right)$ \\
\hline$v_{\mathrm{a}, \mathrm{b}}$ & Collision frequency of a with $\mathrm{b}(\mathrm{Hz})$ \\
\hline$\rho$ & Mass density $\left(\mathrm{kg} / \mathrm{m}^{3}\right)$ \\
\hline$\rho_{0}$ & Mass density in the orifice $\left(\mathrm{kg} / \mathrm{m}^{3}\right)$ \\
\hline$\sigma$ & $\begin{array}{l}\text { Self collision cross section for ions and } \\
\text { neutrals }\left(\mathrm{m}^{2}\right)\end{array}$ \\
\hline$\sigma_{\mathrm{a}, \mathrm{b}}$ & $\begin{array}{l}\text { Collision cross section for a colliding with } b \\
\left(\mathrm{~m}^{2}\right)\end{array}$ \\
\hline & Electron-impact excitation cross-section $\left(\mathrm{m}^{2}\right)$ \\
\hline & Electron-impact ionization cross-section $\left(\mathrm{m}^{2}\right)$ \\
\hline
\end{tabular}

\section{Introduction}

The current carrying capability and long-life of orificed hollow cathodes has made them the primary choice for electric propulsion systems from $100-\mathrm{W}$ to several tens of kilowatts. ${ }^{1}$ For low current devices, the power and propellant consumption of the cathode, in addition to life, are the design drivers. At high current, the ion flux may become sufficient to limit cathode life by erosion, particularly for the ion thruster discharge cathode. ${ }^{2}$ Despite the volume of experience with hollow cathodes in the electric propulsion community, thorough understanding of the plasma phenomena within and near hollow cathodes remains elusive, due in part to the small scale of the devices. Cathode life prediction is hindered by the fidelity of the measurements and calculations of plasma properties within and near the cathode. Several models have been developed previously to examine the insert region or orifice region plasmas separately. A hollow cathode model which considers both the insert and orifice plasma regions is presented in this paper. The model is used to examine plasma properties within the hollow cathode and provides a starting point for examining the plasma downstream of the cathode.

\section{Model Description}

The hollow cathode model presented here is based on a control volume approach to the orifice and insert plasmas respectively. An overview of the cathode model is presented in Figure 1. Conservation of ions and energy, as well as current continuity are applied to each control volume. These sets of equations provide a basis for determining the electron temperature and number density in each region and the insert temperature in the insert region. The orifice model, which is based on the one originally developed by Mandell and Katz, ${ }^{3}$ is presented, followed by the model of the insert region.

\section{Orifice Model}

The orifice model assumes that all of the cathode current is conducted through the orifice, and consequently ion collection to external cathode surfaces is neglected. The plasma within the orifice is treated as quasineutral, and the ions lost to the cathode and the insert region are replaced through electron impact ionization. Energy is deposited into the plasma via ohmic heating, and ionization and convection are the energy loss mechanisms considered. Mandell and $\mathrm{Katz}^{3}$ developed a simple model of the orifice processes based on these conservation equations, and the present derivation includes current continuity.

\section{Conservation of Ions}

The insert region is modeled as a cylindrical control volume bounded by a cathode sheath at the orifice radius, by a double sheath at the entrance to the orifice, and by the exit plane of the orifice. Figure 1 illustrates the orifice model approximations. The chamfer is neglected in the analysis of the control volume. In the formulation of the model, the plasma properties are assumed to be uniform within the orifice, and the radial electric field is neglected. The axial electric field, however, is implicitly included in the orifice model.

The steady-state continuity equation applied to the ions states that the creation and in-flux of ions is balanced by the out-flux.

$$
\frac{d n_{i}}{d t}=0=\left(\frac{d n_{i}}{d t}\right)_{\text {ionization }}+\left(\frac{d n_{i}}{d t}\right)_{\text {in }-f l u x}-\left(\frac{d n_{i}}{d t}\right)_{\text {out }-f l u x}
$$

where $n_{i}$ is the ion number density. The second term is negligible. The double-layer at the entrance to the orifice region repels ions, and the flux of ions from downstream of the orifice, calculated from measured plasma properties, is much smaller than either of the other two terms. ${ }^{4,5}$ Consequently, the term describing ion flux into the orifice is omitted from the model. In 
order to evaluate the first term in Equation (1), a collision analysis was performed, and the derivation appears in Domonkos. ${ }^{6}$ For simplicity, electron-impact ionization was assumed to be the only mechanism for creating ions within the orifice. Equation (2) describes the ionization rate

$$
\begin{aligned}
\left(\frac{d n_{i}}{d t}\right)_{\text {ionization }}= & \left(\pi \frac{d_{o}^{2}}{4} l_{o}\right)\left(\frac{m_{e}}{2 \pi k T_{e}}\right)^{3 / 2} \\
& \times 4 \pi n_{e} n_{o} \int_{0}^{\infty} d v_{e} v_{e}^{3} \sigma_{i o n}\left(v_{e}\right) e^{-\frac{m v_{e}^{2}}{2 k T_{e}}}
\end{aligned}
$$

where $d_{0}$ is the orifice diameter, $l_{0}$ is the straight channel length of the orifice, $m_{e}$ is the mass of an electron, $\mathrm{T}_{e}$ is the electron temperature, $\mathrm{n}_{\mathrm{e}}$ is the electron number density, $\mathrm{n}_{\mathrm{o}}$ is the neutral number density, $v_{\mathrm{e}}$ is the electron velocity and $\sigma_{\mathrm{ion}}\left(v_{\mathrm{e}}\right)$ is the cross section for electron-impact ionization. Equation (2) neglects the drift induced by double layer because in most cases the potential difference is small. The neutral number density is calculated by assuming choked flow at the exit of the orifice

$$
n_{o}=\frac{\dot{m}}{M_{o} A_{o} \sqrt{\gamma R_{s p} T_{o}}}
$$

where $M_{o}$ is the atomic mass of the propellant, $A_{o}$ is the orifice cross sectional area, and the neutral temperature is assumed to be equal to the orifice plate temperature. The orifice plate temperature was estimated based on the experimental data. The integral in Equation (2) is evaluated numerically using the experimental values for the cross-section by Rapp and Englander-Golden. ${ }^{7}$ The ion flux out of the control volume is determined using the Bohm condition at sheath boundaries and the thermal flux at the downstream boundary of the control volume.

$$
\begin{aligned}
\left(\frac{d n_{i}}{d t}\right)_{\text {out }-f u x} & =\frac{I_{i}}{e}=\frac{J_{i}}{e}\left(2 \pi\left(r_{o} l_{o}+r_{o}^{2}\right)\right) \\
& =0.61 n_{i} c_{i}\left(2 \pi r_{o} l_{o}+\pi r_{o}^{2}\right)+\frac{1}{4} n_{i} \overline{v_{t}}\left(\pi r_{o}^{2}\right) \\
& =0.61 n_{e} \sqrt{\frac{k T_{o}}{m_{t}}}\left(2 \pi r_{o} l_{o}+\pi r_{o}^{2}\right)+\frac{1}{4} n_{t} \sqrt{\frac{8 k T_{i}}{\pi m_{t}}}\left(\pi r_{o}^{2}\right)
\end{aligned}
$$

This equation implicitly includes the effects of the radial electric field with the use of the Bohm criterion. At the exit of the orifice, the density is assumed to be sufficient to shield the bulk of the ions from drifting toward cathode surfaces, and the thermal flux of ions is used. The Debye lengths in the orifice indicate that the bulk of the orifice volume is free of the strong radial electric field near the orifice wall. The thermal flux of ions out of the control volume is usually less than ten percent of the total ion loss term. Consequently the density gradient at the exit of the orifice determines the ion motion. The model by Capacci, et al. ${ }^{8}$ included a sheath at the downstream end of the orifice which is neglected in the present derivation. The sudden expansion of the plasma at the orifice exit approximates the conditions of a decaying plasma, and ion transport was hypothesized to occur by ambipolar diffusion. The transport of ions downstream of the orifice in a quasineutral plasma is essential to the theory of spot and plume-mode operation proposed by Mandell and Katz. ${ }^{3}$ In the present model, the emitted ion current is also used to estimate the emitted electron current beyond the keeper.

\section{Current Continuity}

Current continuity is described at the orifice entrance and at the orifice exit. At the entrance, the total discharge current is calculated as the sum of the electron current from the insert region and the ion current to the walls of the orifice less the ion current emitted into the cathode-to-keeper gap.

$$
I_{D}=I_{e, \text { ins }}+I_{i, \text { ori }}-I_{i, e m i t}
$$

The orifice ion current is calculated as part of Equation (4), as is the emitted ion current. The insert electron current is determined using Equation (5). At the downstream end of the orifice, the discharge current is assumed to be the difference between the emitted electron and ion currents.

$$
I_{D}=I_{e, o r i}-I_{i, e m i t}
$$

Equation (7) combines Equations (5) and (6).

$$
\begin{aligned}
& I_{D}=I_{e, i n s}+0.61 n_{e} c_{i} \pi\left(2 r_{o} l_{o}+r_{o}^{2}\right)-\frac{1}{4} n_{e} \bar{v}_{i}\left(\pi r_{o}^{2}\right) \\
& =I_{e, \text { ori }}-\frac{1}{4} n_{e} \bar{v}_{i}\left(\pi r_{o}^{2}\right)
\end{aligned}
$$

This type of accounting is necessitated by estimation of the ion current in the orifice being on the order of ten percent of the total current. The electron current is assumed to increase linearly between the orifice boundaries. While the rest of the orifice plasma model treats all of the properties as spatially invariant, the axial variation of the electron current influences the ohmic heating within the orifice.

\section{Conservation of Energy}

Conservation of energy within the orifice control volume is approximated by equating the ohmic heating with the losses from ionization, radiative decay of excited states, and convection. 


$$
q_{\text {onmic }}=q_{\text {ion }}+q_{\text {ex }}+q_{\text {conv }}
$$

The ohmic heating is calculated using the resistivity based on electron-neutral and electron-ion collisions, as shown in Equation (9) ${ }^{9}$

$$
\eta=\frac{v m_{e}}{n_{e} e^{2}}
$$

where $v$ is the sum of electron-ion and electron-neutral elastic collision frequencies. As an approximation, the electron-ion collision frequency is calculated from the formula in the NRL Plasma Formulary. ${ }^{10}$

$$
v_{e i}=3.9 \ln \Lambda n_{e} T_{e}^{-\frac{3}{2}}
$$

where the dimensions are consistent with those listed in the Nomenclature and the Coulomb logarithm is

$$
\ln \Lambda=23-\ln \left(\frac{\left(10^{-6} n_{e}\right)^{1 / 2}}{T_{e}^{1 / 2}}\right)
$$

An effective value of the electron-neutral elastic collision cross-section is estimated by numerically integrating the velocity dependent elastic collision cross-section data from Brode over the Maxwellian electron population in the same manner as Equation (2). ${ }^{11}$ The effective cross-section is then used to evaluate the electron-neutral elastic collision frequency as defined in Equation (12),

$$
v_{e, o}=\left(n_{o}-n_{e}\right)\left\langle\sigma_{e, o} v_{e}\right\rangle
$$

where the neutral number density based on flow, $n_{o}$, is reduced by the electron density under the quasineutral assumption, and the velocity of the electrons is defined as

$$
v_{e}=\sqrt{\frac{k T_{e}}{m_{e}}}
$$

The factor of $\sqrt{2}$ typically used to calculate the collision frequency is omitted from Equation (12) because the electron velocity is assumed to be much greater than the neutral velocity, thus defining the relative velocity. Since the properties within the orifice are assumed to be constant everywhere, Equation (9) defines the plasma resistivity in the orifice. The electron current in the orifice is assumed to increase linearly toward the orifice exit due to the creation of ions and electrons through collisions with neutrals along the length of the orifice. The variation in the electron current implies an axial variation in electron density, however the electron density was treated as uniform in the orifice control volume for simplicity. The formulation of the ohmic heating term accommodates the axial variation of the electron current. Thus for $\mathrm{x}<1_{0}$

$$
I_{e}(x)=I_{e, i n s}+b x
$$

where $I_{e, \text { ins }}$ and $b$ are determined by the requirement for current continuity, and are defined in Equations (15) and (16), respectively.

$$
\begin{gathered}
I_{e, n s s}=I_{D}-0.61 n_{e} c_{i}\left(2 \pi r_{o} l_{o}+\pi r_{o}^{2}\right) \\
b=\frac{I_{e, o r i}-I_{e, \text { ins }}}{l_{o}}=\frac{1}{l_{o}}\left[0.61 n_{e} c_{i}\left(2 \pi r_{o} l_{o}+\pi r_{o}^{2}\right)\right]
\end{gathered}
$$

Calculation of the ohmic heating of the electrons is modified to account for the variable electron current along the length of the orifice.

$$
q_{\text {ohmic }}=I^{2} R=\frac{\eta}{A_{o}}\left[I_{e, \text { ins }}^{2} l_{o}+I_{e, i n s} b l_{o}^{2}+\frac{1}{3} b^{2} l_{o}^{3}\right]
$$

The ionization power loss due to the flow of ions out of the control volume is the product of the ionization rate, the charge, and the ionization potential:

$$
q_{\text {ion }}=\left(\frac{d n_{i}}{d t}\right)_{\text {ionization }} e \phi_{i}=N_{e o}\left(\pi r_{o}^{2} l_{o}\right) e \phi_{i}
$$

where $\mathrm{N}_{\mathrm{eo}}$ is determined from Equation (2), and $\phi_{\mathrm{i}}$ is equal to $12.12 \mathrm{eV}$ for xenon.

The second term on the right-hand side of Equation (8) describes the power lost from the free electrons as they excite bound electrons within neutral xenon. The energy lost by free electrons in excitation events is calculated similarly to the ionization energy loss. The excitation collision rate in the orifice is (19)

$$
\begin{aligned}
\left(\frac{d n_{e x}}{d t}\right)=\left(\pi r_{o}^{2} l_{o}\right) & \left(\frac{m_{e}}{2 \pi k T_{e}}\right)^{3 / 2} \\
& \times 4 \pi n_{e}\left(n_{o}-n_{e}\right) \int_{0}^{\infty} d v_{e} v_{e}^{3} \sigma_{e x}\left(v_{e}\right) e^{-\frac{m v_{e}^{2}}{2 k T_{e}}}
\end{aligned}
$$

where the collision cross-section data were taken from Hayashi. ${ }^{12}$ The total energy loss of the free electrons to the excitation of the bound electrons is

$$
q_{e x}=\left(\frac{d n_{e x}}{d t}\right) e U_{e x}
$$

where the average energy lost in an excitation event, $\mathrm{U}_{e x}$, is a constrained parameter. Similarly to Mandell and $\mathrm{Katz},{ }^{3}$ the average excitation energy is set to $10 \mathrm{eV}$. 
While this value is representative, provided the overwhelming majority of the excitations are from the ground state, the average excitation energy decreases as the fraction of secondary excitations increases. In order to rigorously evaluate the power loss due to neutral excitation, a detailed ionization model is required. Development of such an ionization model was beyond the scope of the present investigation, and reduced accuracy of the results can be tolerated when using the model to assess the relative capabilities of a given cathode design.

The convective power loss considers the temperatures of the electrons entering the control volume from the insert region and those exiting the orifice:

$$
q_{\text {conv }}=I_{e, o r i} T_{e, o r i}-I_{e, \text { ins }} T_{e, \text { ins }}
$$

The electron temperature in the insert region is solved for in the insert model. In general, the total convection term is a small fraction of the energy lost in neutral excitation.

The ion continuity (1) and energy equations (8) are solved iteratively by using a numerical goal seeking program which varies the electron temperature and number density, respectively. First the electron temperature is varied to satisfy Equation (1). Next, the number density is determined, satisfying Equation (8). If the solution of Equation (1) holds within established limits, the solution is considered to have converged.

After the orifice model solution converges, several Knudsen numbers are calculated to verify that the plasma is indeed collisional, and the Debye ratio and particle count in a Debye sphere are evaluated to determine if the ionized gas meets the conditions for a plasma. The results showed that the plasma was collisional with Knudsen numbers generally much less than one for plasma-related collisions. The Knudsen numbers for neutral and ion self-collisions were as high as a few tenths. This is considered borderline for any continuum theory describing their properties.

\section{Insert Model}

In the same spirit as the orifice model, the plasma in the insert region is approximated by a control volume with uniform plasma properties throughout. Figure 1 illustrates the basis for the insert model. The efficiency of the ionization processes within the insert region is expected to contribute to the overall performance. In addition to the statements of ion continuity and energy conservation, the insert model has an explicit statement of current continuity. These three equations still leave four free parameters, and the choice of those parameters is discussed.

\section{Current Continuity}

In the insert region, the current continuity statement is written by equating the total operating current, $\mathrm{I}_{\mathrm{D}}$, with the current emitted from and collected at the cathode surface. This approach necessitates inclusion of the ion current in the orifice, and the statement is therefore dependent upon the results of the orifice model calculations. The mathematical expression representing current continuity is written in Equation (22).

$$
I_{D}=I_{e, e m i t}+I_{i, \text { coll }}-I_{e, \text { coll }}-I_{i, \text { emit }}
$$

The first term in Equation (22) refers to the thermionic electron emission current from the insert which is determined using the Richardson-Dushman equation.

$$
I_{e, e m i t}=I_{e, t h}=\left(2 \pi r_{i} L_{e f f}\right) A_{R} T_{i n s}^{2} e^{-\frac{\phi_{e f f}}{k T_{i n s}}}
$$

The value of the Richardson coefficient was set constant at $60-\mathrm{A} / \mathrm{cm}^{2}-\mathrm{K}^{2}$ which is consistent with Goodfellow. ${ }^{13}$ The work function is considered as a bounded free parameter. Typical values for the work function of the insert range from 2.0 to $2.1-\mathrm{eV}$, and the variation of the thermionic current density as a function of temperature is plotted in Figure 2. ${ }^{14}$ An effective work function is used to account for the Schotky effect which acts to reduce the apparent work function of a material in the presence of a strong electric field.

$$
\phi_{e f f}=\phi_{o}-\sqrt{\frac{e\left|E_{d s}\right|}{4 \pi \varepsilon_{o}}}
$$

A double sheath analysis for an electron emitting surface estimates the electric field in Equation (24) to $\mathrm{be}^{15,16}$

$$
E_{d s}=\sqrt{\frac{n_{e} k T_{e}}{\varepsilon_{o}}}\left[2 \sqrt{1+2 \frac{e V_{p}}{k T_{e}}}-4\right]^{1 / 2}
$$

The plasma potential in Equation (25) is a restricted parameter in this investigation. Experimental data showed that the plasma potential varied between 8 and $12-\mathrm{V}$ above the cathode potential depending upon axial position. ${ }^{22}$ The effect of the plasma potential on the thermionic current density is depicted in Figure 3 for plasma parameters similar to those expected. While the emission current density is relatively insensitive to the plasma potential, the Schotky effect increases the emission current density significantly.

The ion current collected at the cathode surfaces includes the ion flux in the orifice and insert regions. Ion backstreaming to the insert region is also calculated using the Bohm criterion, and these ions are assumed to recombine on the cathode surface in the insert region. 
Additionally, the plasma ions, generated in the insert region, also contribute to the ion current. In the context of the control volume approximation, ions enter the cathode sheath at the Bohm velocity and diffuse upstream at the thermal velocity. Ions diffusing upstream were also assumed to recombine on the cathode surface.

Ion emission and electron backstreaming are both small terms, however they are included for completeness. Electron backstreaming to the insert surface is described using Equation (26)

$$
I_{e, b a c k}=\frac{1}{4} n_{e} \bar{v}_{e} e A_{e f f} e^{-\frac{e V_{p}}{k T_{e}}}
$$

which is on the order of a few milliamperes typically. The effective surface area for electron collection, $A_{\text {eff }}$, includes both the effective emission region of the insert and the orifice plate surface. Diffusion of electrons upstream of the insert control volume is neglected based on the assumption that the axial electric field overwhelms the tendency of any electrons to diffuse in that direction.

\section{Ion Conservation}

This species specific form of conservation of mass is essentially the same as that used in the orifice mode, Equation (1). The primary difference is the consideration of two electron populations: one a beam from the thermionic emission through a double sheath, and the other the Maxwellian plasma electrons. The contribution of the plasma electrons to the creation of ions and excited atoms is exactly that prescribed by Equations (2) and (19) using the insert effective volume.

The electrons emitted from the insert are referred to here as the primary electrons. The primary electron speed distribution function is approximated as

$$
f\left(v_{e}\right)=4 \pi\left(\frac{m_{e}}{2 \pi k T_{i n s}}\right)^{\frac{3}{2}} v_{e}^{2} e^{-\frac{m_{e}\left(v_{e}-v_{d}\right)^{2}}{2 k T_{\text {ins }}}}
$$

where $v_{d}$ is the electron drift velocity induced by the sheath voltage, and the temperature of the primary electron beam is assumed to be the insert temperature. Since the primary electrons are created at the insert, excitation and ionization collisions deplete the population with increasing distance from the insert. The mean free path for either of these collisions is calculated as shown in Equation (28)

$$
\begin{aligned}
\lambda & =\frac{1}{n \sigma} \\
& =\left[n 4 \pi\left(\frac{m_{e}}{2 \pi k T_{e}}\right)^{\frac{3}{2}} \int_{0}^{\infty} d v_{e} v_{e}^{3} \sigma\left(v_{e}\right) e^{\frac{m_{e}\left(v_{e}-v_{b}\right)^{2}}{2 k T_{e}}}\right]^{-1}\left\langle v_{e}\right\rangle
\end{aligned}
$$

where the number density is that of the target. Figure 4 depicts the electron impact cross-sections for xenon. $^{17,18,19}$ Below $20-\mathrm{V}$, primary electrons emitted from the insert are more likely to undergo an excitation collision than an ionization event. Measured plasma potentials within the insert region are $14-\mathrm{V}$ and lower. ${ }^{22}$ Evaluation of Equation (28) for the electron-impact excitation cross-section and the electron-impact ionization cross-section indicates that the mean free path for the ionization interaction is at least 10 times greater than for excitation in the range of plasma potentials observed experimentally. ${ }^{22}$ For simplicity, a planar geometry is used to approximate the primary electron number density at the mean free path for electron-impact ionization.

$$
n_{e, p r}\left(r_{o}-\lambda_{\text {ion }}\right)=n_{e, p r}\left(r_{o}\right)\left[1-\operatorname{erf}\left(\frac{\lambda_{\text {ion }}}{\lambda_{e x}}\right)\right]
$$

For $\lambda_{\text {ion }}>>\lambda_{\text {ex }}$, the contribution of electron-impact ionization by the primary electrons is negligible, and consequently this ionization mechanism was neglected. Nevertheless, the primary electrons are expected to contribute strongly to ionization. The only mechanisms considered for ion creation are electron-impact ionization by plasma electrons, and step-wise excitation by both the primary and plasma electrons, leading to ionization. The latter phenomenon is considered without a rigorous derivation of the contribution of this term. However, calculated excitation collision frequencies for the primary electrons in the insert region are on the order of or greater than the Einstein coefficients for neutral xenon, indicating the feasibility of a multi-step ionization process. ${ }^{20}$ In the model, a fixed percentage of the excitation collisions are assumed to create ions. The resulting expression describing the ion production in the insert region is 


$$
\begin{aligned}
& \left(\frac{d n_{i}}{d t}\right)_{\text {ionization }}=\left(\pi r_{i}^{2} L_{e f f}\right) \\
& \quad \times\left(\left(\frac{m_{e}}{2 \pi k T_{e}}\right)^{3 / 2} 4 \pi n_{e} n_{o} \int_{0}^{\infty} d v_{e} v_{e}^{3} \sigma_{i o n}\left(v_{e}\right) e^{-\frac{m v_{e}^{2}}{2 k T_{e}}}\right) \\
& +f_{e x}\left[\pi\left(r_{i}^{2}-\left(r_{i}-2 \lambda_{e x}\right)^{2}\right) L_{e f f}\right]\left(\frac{m_{e}}{2 \pi k T_{\text {ins }}}\right)^{3 / 2} \\
& \quad \times 4 \pi n_{e, p r}\left(n_{o}-n_{e}\right) \int_{0}^{\infty} d v_{e} v_{e}^{3} \sigma_{e x}\left(v_{e}\right) e^{-\frac{m v_{e}^{2}}{2 k T_{i n s}}}
\end{aligned}
$$

The percentage of excitation collisions which create ions $f_{e x}$ is one of the free parameters in the insert model, and was expected to be a few percent at most. The effective volume for the excitation of neutrals is limited to two mean free paths from the insert. This adjustment accounts for the depletion of primary electrons beyond this distance from the insert.

Ion creation by collisions of electrons with neutrals and ion in-flux from the orifice are balanced by ion convection across the control-volume boundaries. Plasma ions enter the cathode sheaths at the insert radius and at the orifice plate with a flux determined by the Bohm condition. Ion loss from the control volume is also calculated by the thermal flux to the upstream boundary. The various fluxes calculated in this section are also useful in determining the conservation of energy within the orifice.

\section{Conservation of Energy}

The conservation of energy in the insert region is written for the plasma as a whole. Energy enters or is released in the control volume by electron convection from the insert, ion convection from the orifice region, and Ohmic heating. The energy convected with the thermionic electrons is

$$
q_{\text {thm }}=I_{e, t h m}\left(V_{f}+\frac{3 k T_{i n s}}{2 e}\right)
$$

where the fall voltage, $V_{f}$, is approximated by the plasma potential. The energy convected with the orifice ions is

$$
q_{i, o r i}=\left(0.61 n_{e} c_{i} e \pi r_{o}^{2}\right)_{o r i}\left(V_{d s}+\frac{2 k T_{i}}{e}\right)
$$

where the average thermal energy of the ion flux to the upstream orifice boundary is $2 k T_{i}$ because the energy transport favors the high-energy particles. ${ }^{21}$ The voltage drop across the double sheath at the boundary between the insert and orifice regions, $V_{\mathrm{ds}}$, was estimated by Capacci, et al. ${ }^{8}$ to be

$$
V_{d s}=\left(\frac{9 I_{D} k T_{e}}{7.5 A_{o} n_{e} e^{2}} \sqrt{\frac{m_{e}}{2 e}}\right)^{2 / 3} .
$$

Ohmic heating is calculated in a similar manner as described for the orifice. The plasma resistivity is determined assuming uniform density and temperature. The electron current to the orifice calculated from Equation (5) is used for the Ohmic heating calculation. Since the current is carried mostly in the radial direction, an average cross-sectional area for current conduction is used. The resulting expression for the Ohmic heating is

$$
q_{\text {oimic }}=I_{e, \text { ins }}^{2} \eta \frac{r_{i}}{4 / 3 r_{i} L_{e f f}} .
$$

The energy loss mechanisms from the insert region are ion loss, excitation collisions, electron convection of the current, and electron backstreaming to the insert. The ion loss term is calculated based on the ion flux to the boundaries of the control volume.

$$
\begin{aligned}
q_{i, \text { ass }} & =\left[0.61 n_{e} c_{i} e\left(2 \pi r_{i} L_{e f f}+\pi\left(r_{i}^{2}-r_{o}^{2}\right)\right)+\frac{1}{4} n_{e} \bar{v}_{i} e\right] \\
& \times\left(\phi_{i}+\frac{2 k T_{i}}{e}\right)
\end{aligned}
$$

The energy lost in excitation collisions is calculated as the product of the rate of excited neutral production and the average excitation energy.

$$
\begin{aligned}
q_{e x} & =\left(\frac{d n_{e x t a t e d}}{d t}\right) e U_{e x} \\
& =\left[n_{e}\left(n_{o}-n_{e}\right)\left\langle v_{e} \sigma_{e x}\right\rangle_{p}\left(2 \pi r_{o} L_{e f}\right)+n_{e, p r}\left(n_{o}-n_{e}\right)\left\langle v_{e} \sigma_{e x}\right\rangle_{p r}\right] e U_{e s}
\end{aligned}
$$

where the average excitation energy $U_{e x}$ is another free parameter. The value of $U_{e x}$ is somewhat lower than in the orifice because the energy lost by electrons in secondary excitation collisions, which play an important role in ionization in the insert region, is less than $4-\mathrm{eV}$, thereby reducing the average energy compared to the case where only ground-state excitation occurs. For most of the results presented, $U_{e x}$ is set equal to $5-\mathrm{eV}$ for the insert region, and a sensitivity analysis was conducted. The energy lost by electron conduction of the current is

$$
q_{e, c o n}=\frac{I_{e, \text { ins }}}{e} 2 k T_{e}
$$


where $T_{e}$ is the Maxwellian electron temperature in the insert region. The insert electron temperature calculated from this model could be used as an input for the orifice model. Since the orifice model is relatively insensitive to this parameter, an average value of the insert temperature is used to expedite the solution. Finally, the electron backstreaming component of the energy equation is

$$
q_{e, b a c k}=\frac{I_{e, b a c k}}{e} 2 k T_{e}
$$

The solution method for the insert model is essentially the same as for the orifice model. Ion continuity is satisfied by varying the electron temperature. Conservation of energy is achieved by solving for the electron number density, and the insert temperature is varied to achieve current continuity. Both the orifice and insert models were run with inputs matching those for the experimental set-up, and the results are discussed in the next section.

\section{Model Predictions}

The inputs for the orifice and insert models are the current, flow-rate, cathode material, and cathode geometry. By using the same inputs available to an experimental investigation, the results of the model are directly comparable to the experimental data. In this investigation, the geometry of a $3.2-\mathrm{mm}$ diameter hollow cathode 22 was input to the orifice and insert models, and the flow-rate and current were varied over the range tested experimentally. Additionally, the models were also used to evaluate the effects of geometry and material changes for low-current cathodes. While the standard operating procedure for the models was to vary only the parameters controllable in an experimental situation, several free parameters remained. The model was evaluated to test the sensitivity of the various solutions to the free parameters.

\section{Sensitivity of the Orifice Results to the Free Parameters}

The orifice model neglects the creation of ions by stepwise excitation, and the calculated Knudsen numbers for this type of collision indicate that this phenomenon occurs infrequently. Nevertheless, the effects of a fixed percentage of the excitation collisions creating ions were evaluated, and the results are plotted in Figure 5. Unless stated otherwise, all the results presented here refer to the cathode AR6 of Reference 22. The number density shows the largest change, monotonically increasing with $\mathrm{f}_{\mathrm{ex}}$. In terms of a figure of merit for cathode optimization, the ohmic heating and excitation energy loss both scaled with nearly a ten percent reduction for every five percent increase in $f_{\text {ex }}$. Since the Knudsen numbers suggested that step-wise ionization was the exception in the orifice, $f_{e x}$ was set to zero for subsequent calculations.

The average excitation energy is also considered a free parameter since the distribution of the excitation transitions was unknown. Excitation from the ground state in xenon costs between 8.44 and $10.40-\mathrm{eV}^{23}$ If this event dominates the excitation collisions, then the average excitation energy is on the order of $10-\mathrm{eV}$. While the preceding paragraph discounted the contribution of step-wise excitation in the orifice, the effect of reducing the average excitation energy was evaluated to examine the potential consequences of this simplification, and the results are shown in Figure 6 . The most sensitive parameters are the number density and the power consumption. The power consumption was expected to scale with the excitation energy. The number density increases as the excitation energy decreased, ensuring that the convective power terms account for the difference between the ohmic heating and the excitation loss. The previous discussion concerning the orifice Knudsen number for excitation supports the conclusion that ground state excitations dominate, and the average excitation energy was set to $10-\mathrm{eV}$ for all subsequent calculations.

\section{Sensitivity of the Insert Results to the Free Parameters}

By contrast, the excitation processes in the insert region are essential to plasma generation. The primary electrons undergo excitation collisions almost exclusively. Figure 7 depicts the sensitivity of insert region plasma parameters and power consumption to the value of $\mathrm{f}_{\mathrm{ex}}$ in the insert region. Electron convective power consumption decreases by ten percent for an increase of two percent to $f_{e x}$, while the number density increases by twenty percent over the same interval. Although the number of excitation events possible in xenon argue that only a small fraction create ions, an ionization model is needed to rigorously determine the value of $f_{e x}$. The fraction of excitations creating ions was set to 0.05 for all subsequent calculations, since the results agreed well with the experimental data.

As important as the value of $f_{\text {ex }}$ is to the solution of the insert region parameters, the average excitation energy in the insert region influences the solution to a greater degree. Figure 8 depicts the sensitivity of the plasma properties and energy terms in the insert region to changes in the average excitation energy. While the plasma properties and energy terms are highly sensitive to $U_{e x}$, the preponderance of the secondary excitations in the insert region is expected to reduce the average 
excitation energy compared with the ground-state value used in the orifice calculations. Over the range from 3 to $8-\mathrm{eV}$, the change in power consumption by excitations scales with $U_{e x}$. The number density is highly sensitive to the average excitation energy in the insert region, changing by about ten percent per electron-Volt. Since many of the possible transitions between excited states in neutral xenon involve less than $1-\mathrm{eV},{ }^{23}$ the lack of detailed accounting of the population of the excited states makes the value chosen for $U_{\text {ex }}$ somewhat arbitrary, although it should be weighted for the ground-state transitions which enable secondary excitations. The average excitation energy was set to $5-\mathrm{eV}$ in lieu of a more rigorous evaluation. This number accounts for electron collisions with excited states while a lower number requires that the plasma approach optically thick conditions. The experimental data indicated that the insert region plasma was far from optically thick conditions.

The plasma potential is a free parameter in the insert model, although experimental data put bounds on the value chosen. Furthermore, the sharp axial gradient in the plasma potential made the choice of a volumeaveraged value perilous. The plasma potential was varied from 7 to $12-\mathrm{eV}$ to obtain the data in Figure 9. Again the number density is highly sensitive to this parameter as is the convected energy from the thermionic emission current. The latter finding is expected since the reduction in the work function by the Schotky effect scales with number density. While the insert region plasma potential near the insert was as high as $12-\mathrm{V}$, a value of $8-\mathrm{V}$ was used for subsequent calculations both in consideration of the volume averaged value and because large values for $V_{p}$ degraded the stability of the model.

The final free parameter considered here is the material work function of the insert. While the available data confine the work function to between 2.0 and $2.1-\mathrm{eV}$, this range strongly affects the requisite cathode operating temperature as shown in Figure 10. A change of $0.1-\mathrm{eV}$ in the work function leads to more than a $50-\mathrm{K}$ increase in the insert temperature. It should be noted that in a real system, the plasma potential depends upon the material work function, and the variation of either of these parameters independently is artificial. A value of $2.00-\mathrm{eV}$ was chosen for subsequent calculations primarily due to an apparent over-prediction of power consumption; a low-work function reduces the power consumption gap at high flow-rates.

\section{Sensitivity of Predicted Cathode Power}

A comparison of the sensitivity of cathode power consumption to variations in several of the free parameters is depicted in Figure 11. Cathode power is most strongly tied to the choice for the average energy of excitation collisions within the orifice. The fraction of excitation collisions resulting in ionization in the orifice and the plasma potential in the insert region exert comparable influence on the predicted cathode power consumption. The average energy transferred in an excitation collision in the insert volume influences cathode power consumption in a non-linear fashion, and the magnitude of dependence of cathode power on the average excitation energy in the insert region is less than the dependence upon the other free parameters. Plots similar to Figure 11 provide insight into the suitability of the model predictions for use in cathode design. If the variability in the free parameters is minimized, the model predictions become more reliable.

\section{Comparison of Cathode Power Consumption with Experimental Data}

The model predictions are directly compared with experimental data for a 3.2-mm diameter hollow cathode in Figure 12. The average excitation energy and the fraction of excitation collisions resulting in ionization were varied in an attempt to match the experimental data. The predicted power consumed in the orifice is plotted in Figure 12, along with the total power consumed experimentally. In order for the predicted power in the orifice to be consistent with the total power measured, the free parameters were set well beyond the bounds discussed above. The control volume approach appears to be too simplistic to capture the subtleties of hollow cathode operation at low current. Observation of Figure 12 indicates that in spot mode, the measured cathode power consumption was nearly invariant with flow rate. The positive slope of the predicted power consumption results from Equations (18) and (19), where the increase in neutral density from the flow rate results in additional power losses for the control volume.

\section{Insights from Calculated Plasma Parameters}

The ability of the model to predict the plasma conditions within the cathode was also evaluated. Figure 13 depicts the variation of the plasma properties within the cathode AR3 from Reference 22. The insert region is the only location where the experimental data overlaps with the model. In the insert region the predicted, bulk-averaged electron number density and temperature match the experimental results. Since models are currently the only means to evaluate the plasma properties within the orifice and the model appears to predict plasma properties to within a small error, the cathode model presented here was used to gain insight into the processes governing current 
conduction in the cathode. The large gradient in number density and the modest gradients in electron temperature both upstream and downstream of the orifice suggest the presence of at least one double layer. The model assumes a double layer at the orifice entrance, and the rapid expansion at the exit of the orifice provides evidence of a double layer in this region as well. The downstream double layer may enable the electrons in the orifice to gain sufficient energy to ionize local to the orifice, thereby creating the spot and facilitating current conduction.

\section{Comparison with the Space Station Plasma}

\section{Contactor}

Although the cathode model was originally developed as a design tool for low-current hollow cathodes, an attempt was made to assess its performance in predicting the operation of existing hollow cathodes. The Space Station Plasma Contactor (SSPC) is one of the most widely tested hollow cathodes and is ideal for comparison purposes. Figure 14 shows the predicted orifice power consumption in the SSPC, and the total power consumption of the SSPC at 3.0-A discharge is also shown for comparison. ${ }^{24}$ Unlike the low-current hollow cathode results, the predicted orifice power is less than the total experimental value. Additionally the predicted trends of orifice power consumption with flow-rate more closely approximate the independence of total power on the flow rate in spot mode. From this comparison, the assumptions made in the cathode model appear to be better suited to the operation of larger and higher-current cathodes than originally intended. This suggests that the dominant physical processes for small hollow cathodes are different than large devices.

\section{Conclusions}

A model of the orificed hollow cathode, based on particle and energy balances, was presented. The model included the plasma in both the insert and orifice regions. In the orifice region, a single component, Maxwellian electron population was assumed to generate the ions and carry the bulk of the current. Models for the boundaries of the orifice plasma were presented. In the insert region, both a primary beam, thermionic and background Maxwellian electron populations were assumed to sustain the plasma and the current. The insert region current emission was constrained by the calculated current required by the orifice region.

The sensitivity of the model to the various free parameters was assessed for low-current hollow cathodes. The cathode power consumption was found to be a strong function of the average excitation energy within the orifice, the fraction of excitation collisions resulting in ionization in the orifice, and the plasma potential in the insert region. Comparisons were made with experimental results to evaluate the utility of the model. A fundamental limitation of the energy balance calculation was discussed, and was found to be most critical for small-geometry devices at low-current. Additionally, the model when combined with experimental data suggested the presence of doublelayers at the entrance and exit of the orifice. 


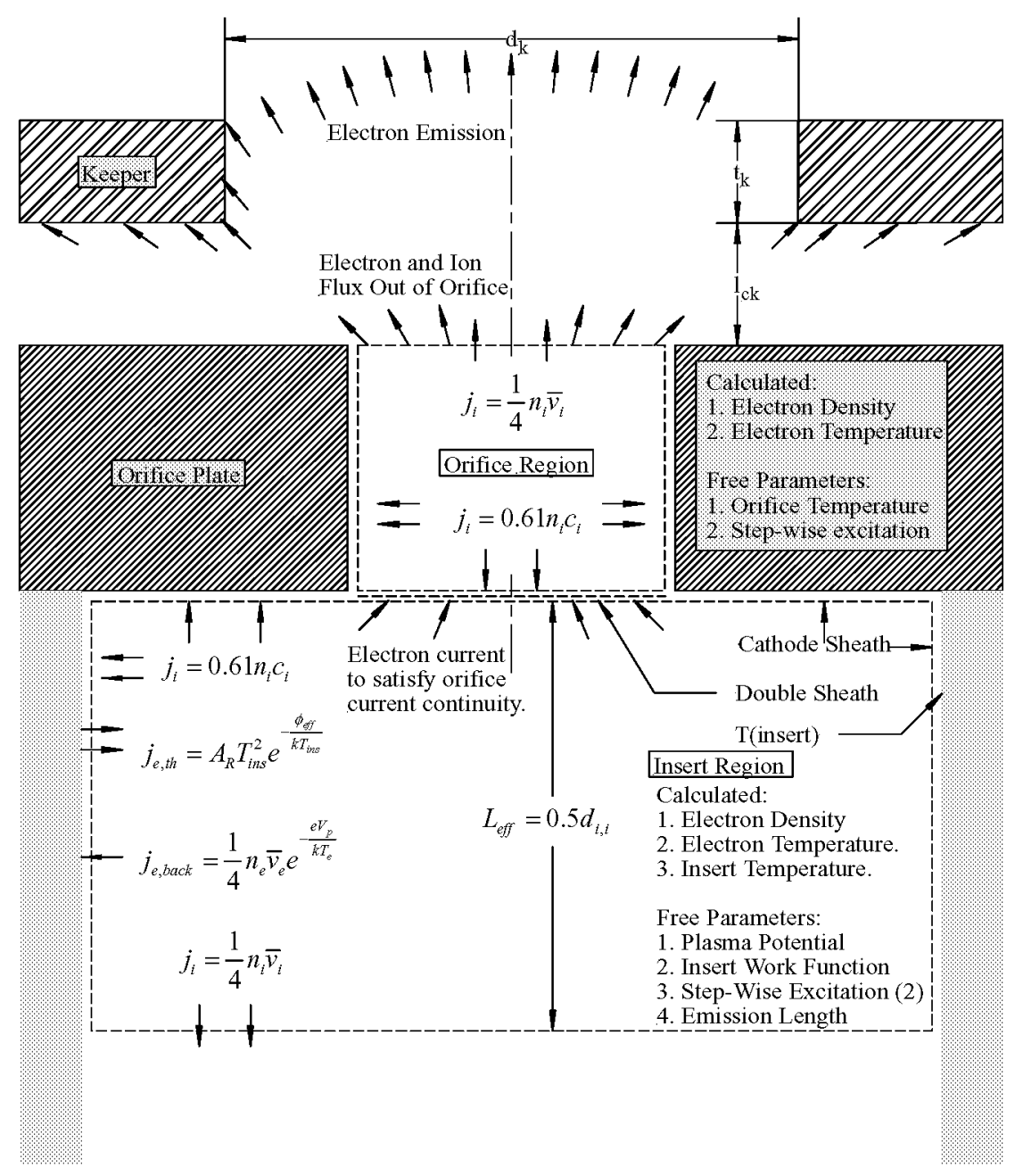

Figure 1 - Illustration of the Orifice and Insert Model Approximations.

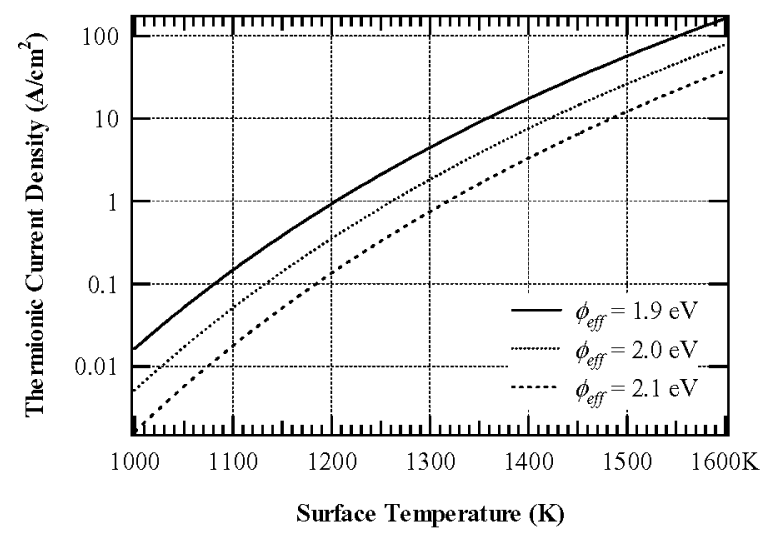

Figure 2 - Thermionic Current Density for Various Effective Work Functions. 


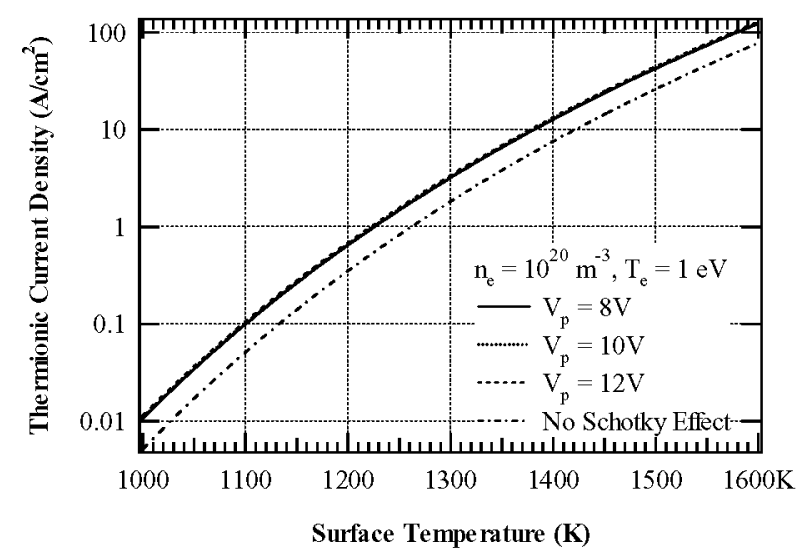

Figure 3 - Dependence of the Thermionic Emission Current Density on the Plasma Potential Based on Double Sheath Analysis. Material Work Function $=2.0-\mathrm{eV}$.

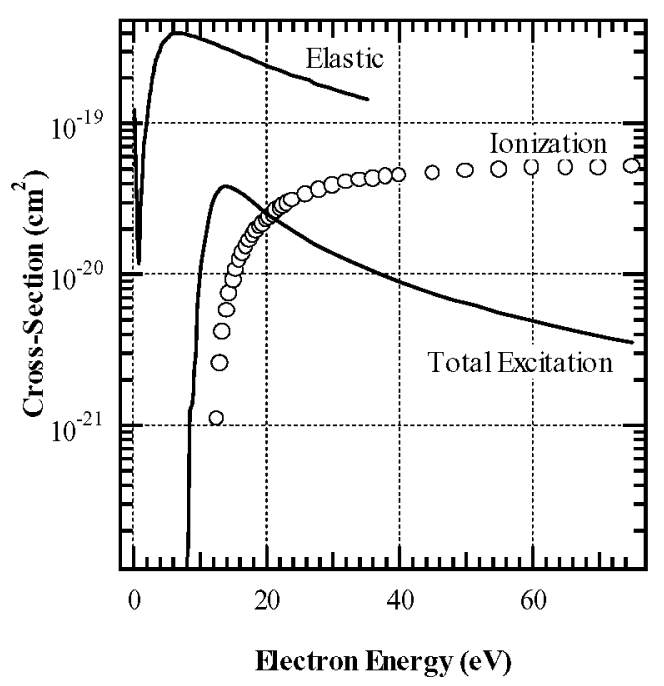

Figure 4 - Electron Impact Cross-Sections for Xenon. ${ }^{17,18,19}$

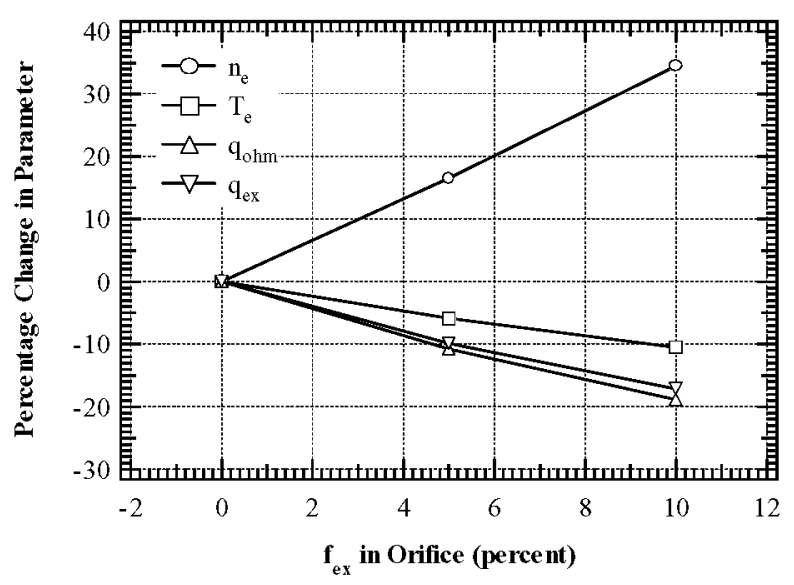

Figure 5 - Relative Dependency of Orifice Plasma Properties on the Fraction of Excitation Collisions Contributing to Ionization. AR6 Geometry at $0.50-\mathrm{A}$ and $0.9-\mathrm{sccm}$. 


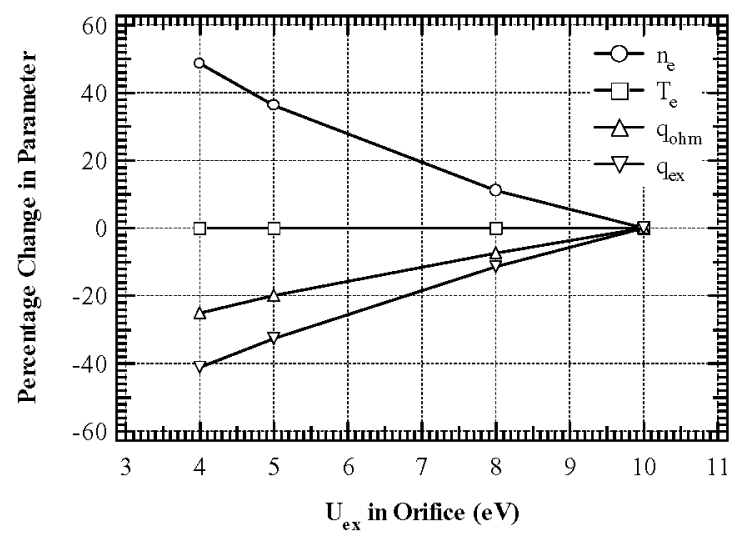

Figure 6 - Relative Dependency of the Orifice Region Plasma Properties on the Average Excitation Energy. AR6 Geometry at $0.5-\mathrm{A}$ and $0.9-\mathrm{secm}$.

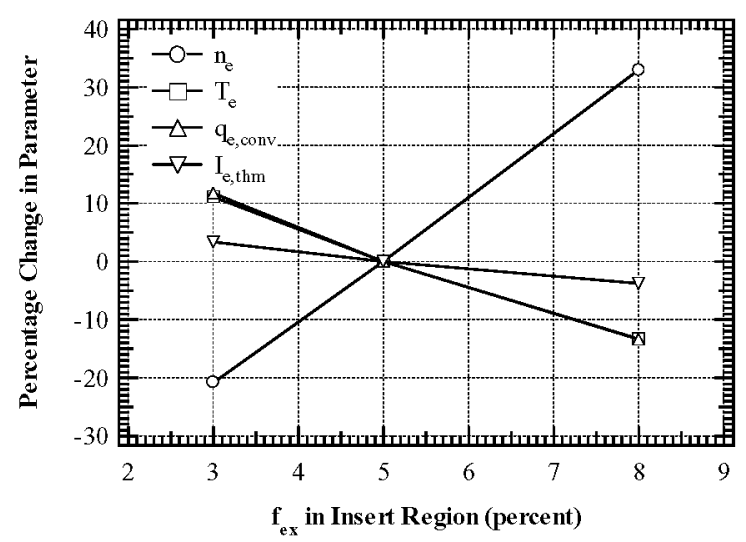

Figure 7 - Dependency of the Insert Region Plasma Properties on the Fraction of Excitation Collisions Contributing to Ionization. AR6 Geometry at $0.50-A$ and $0.9-\mathrm{sccm}$.

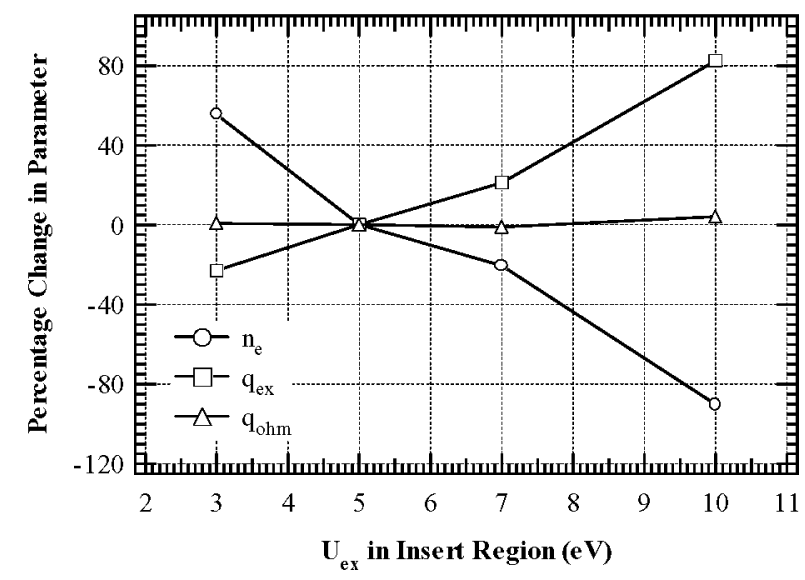

Figure 8 - Dependency of the Insert Region Plasma Properties on the Average Excitation Energy. AR6 Geometry at $0.50-\mathrm{A}$ and $0.9-\mathrm{sccm}$. 


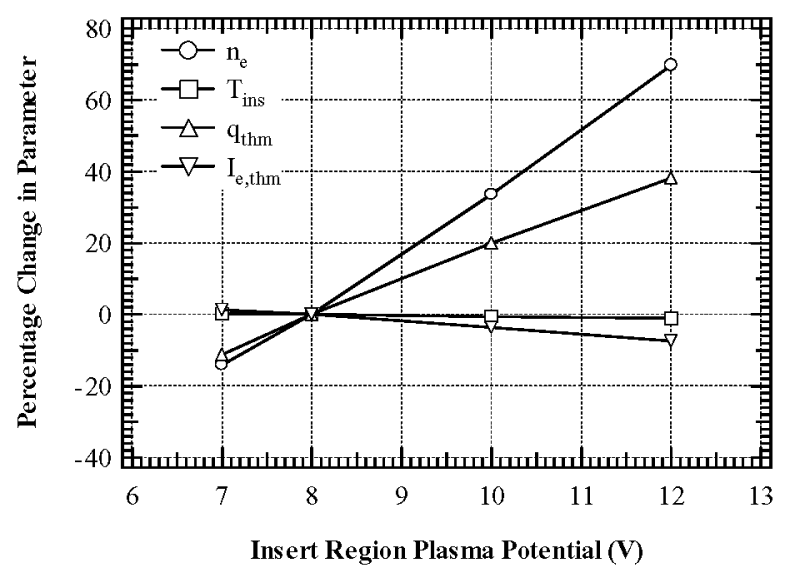

Figure 9 - Dependency of the Insert Region Plasma Parameters on the Plasma Potential. AR6 Geometry at $0.50-\mathrm{A}$ and $0.9-\mathrm{sccm}$.

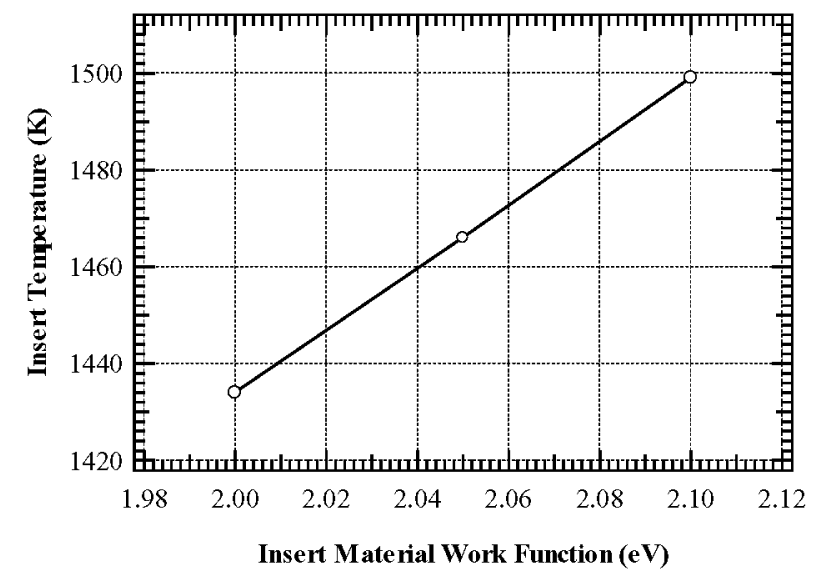

Figure 10 - The Effect of the Material Work Function on the Predicted Insert Temperature for AR6 at $0.50-\mathrm{A}$, and $0.9 \mathrm{sccm}$. 


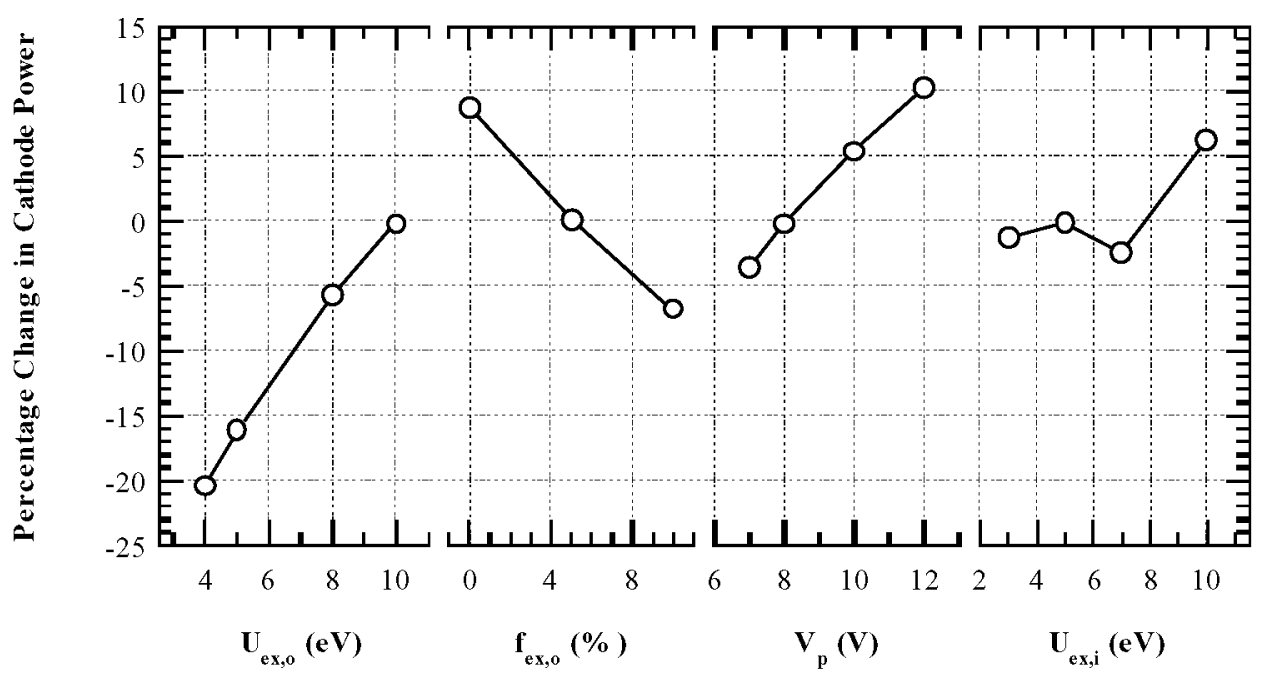

Figure 11 - Sensitivity of the Predicted Power to the Free Parameters for a Hollow Cathode Operating at 0.50-A.

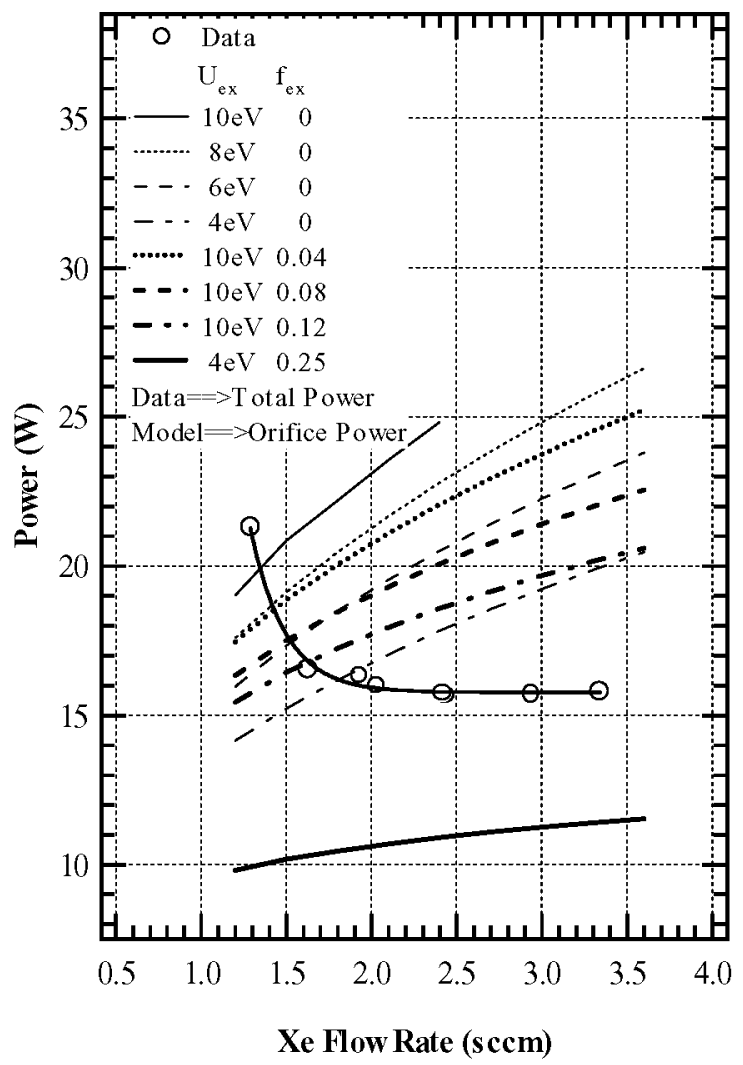

Figure 12 - Variation of Predicted Orifice Power Consumption Compared with Measured Cathode Performance. ${ }^{22}$ The Calculated Dependency and Magnitude Indicate that the Bulk Averaged Plasma Properties Over-Predict the Ion Losses. 


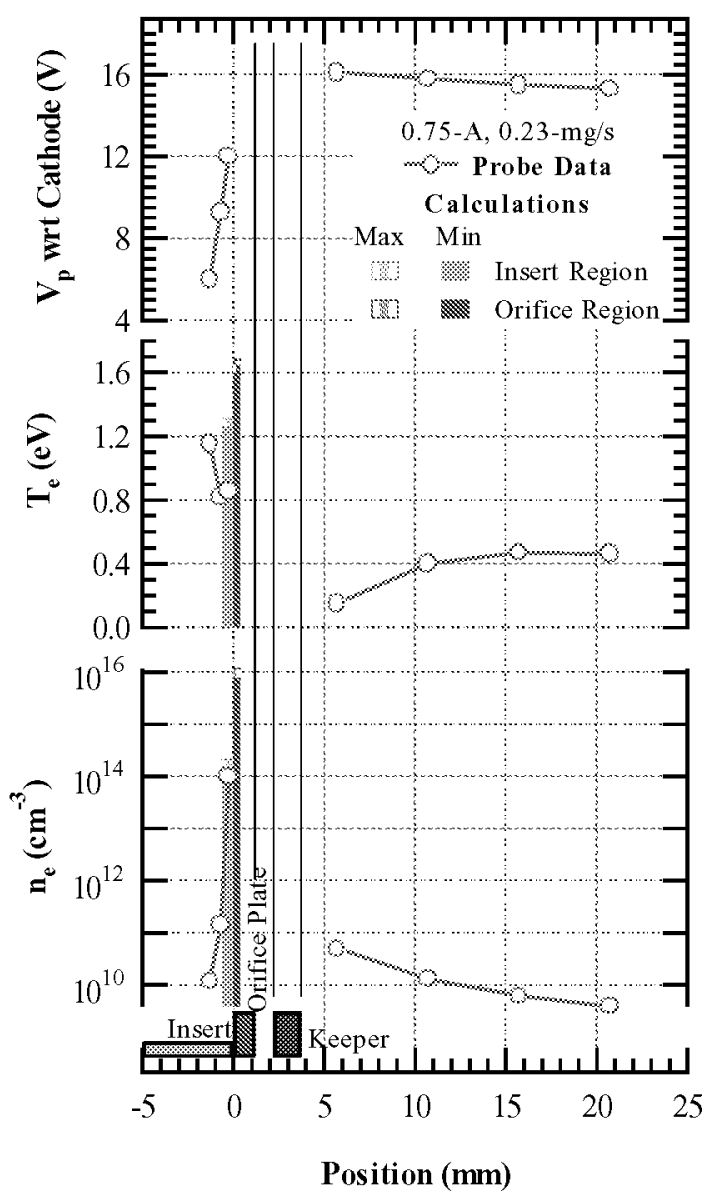

Figure 13 - Measured and Calculated Plasma Properties of a Hollow Cathode. ${ }^{22}$ Calculated Volume Averaged Density in the Orifice Region Suggest the Presence of One or More Double Layers at the Upstream and/or Downstream Boundaries.

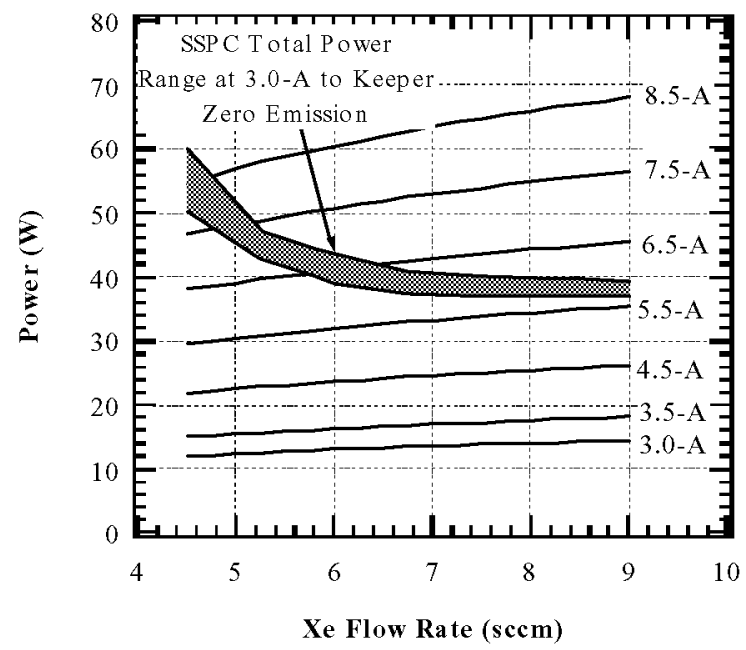

Figure 14 - Calculated Power Consumption in the Orifice of the Space Station Plasma Contactor Showing a More Modest Dependence Upon Flow Rate. ${ }^{24}$ 


\section{References}

${ }^{1}$ Patterson, M.J., et al., "Ion Propulsion Development Activities at NASA Glenn Research Center," AIAA Joint Propulsion Conference Paper No. 2000-3810, July 2000.

${ }^{2}$ Domonkos, M.T., Foster, J.E., Patterson, M.J., and Williams, G.J., "Investigation of Keeper Erosion in the NSTAR Ion Thruster," IEPC Paper No. 01-308, $27^{\text {th }}$ International Electric Propulsion Conference, Pasadena, CA, Oct. 2001.

${ }^{3}$ Mandell, M.J. and Katz I., "Theory of Hollow Cathode Operation in Spot and Plume-modes," AIAA Paper No. 94-3134, 30 ${ }^{\text {th }}$ AIAA/ASME/SAE/ASEE Joint Propulsion Conference, Indianapolis, IN, June 1994.

${ }^{4}$ Anders, A. and Kühn, M., "Characterization of a Low-Energy Constricted-Plasma Source," Review of Scientific Instruments, Vol. 69, No. 3, Mar. 1998, pp. 1340-1343.

5 Williams, G., Smith, T., Domonkos, M., Shand, K, and Gallimore, A., "Laser Induced Fluorescence Characterization of Ions Emitted from a Hollow Cathode," AIAA Paper 99-2862, 35 ${ }^{\text {th }}$ AIAN/ASME/SAE/ASEE Joint Propulsion Conference, Los Angeles, CA, June 1999.

${ }^{6}$ Domonkos, M.T., "Evaluation of Low-Current Orificed Hollow Cathodes," Ph.D. Dissertation, The University of Michigan, 1999.

${ }^{7}$ Rapp, D. and Englander-Golden, P., "Total Cross Sections for Ionization and Attachment in Gases by Electron Impact. I. Positive Ionization," The Journal of Chemical Physics, Vol. 43, No. 5, Sept. 1, 1965, pp. 1464-1479.

${ }^{8}$ Capacci, M., Minucci, M., Severi, A., "Simple Numerical Model Describing Discharge Parameters in Orificed Hollow Cathode Devices," AIAA Paper No. 97-2791, 33 ${ }^{\text {rd }}$ AIAA/ASME/SAE/ASEE Joint Propulsion Conference and Exhibit, Seattle, WA, July 1997.

${ }^{9}$ Chen, F.F., Introduction to Plasma Physics and Controlled Fusion, Volume 1: Plasma Physics, Plenum Press, New York, 1984.

${ }^{10}$ Huba, J.D., editor, Naval Research Laboratory: Plasma Formulary, NRL/PU/6790 -94-265, 1994.

${ }^{11}$ Brode, R.R., "The Quantitative Study of the Collisions of Electrons with Atoms," Reviews of Modern Physics, Vol. 5, Oct. 1933, pp. 257-279.

${ }^{12}$ Hayashi, M., "Determination of Electron-Xenon Total Excitation Cross-Sections, from Threshold to $100 \mathrm{eV}$, from Experimental Values of Townsend's $\alpha$," Journal of Physics D: Applied Physics, Vol. 16, 1983, pp. 581-589.

${ }^{13}$ Goodfellow, K.D., A Theoretical and Experimental Investigation of Cathode Processes in Electric Thrusters, Ph. D. Dissertation, The University of Southern California, 1996.

${ }^{14}$ Shroff, A.M., Palluel, P., and Tonnerre, J.C., "Performance of Life Tests of Various Types of Impregnated Cathodes," Applications of Surface Science, Vol. 8, 1981, pp. 36-49.

${ }^{15}$ Siegfried, D.E. and Wilbur, P.J., "A Model for Mercury Orificed Hollow Cathodes: Theory and Experiment," AIAA Journal, Vol. 22, No. 10, Oct. 1984, pp. 1405-1412.

${ }^{16}$ Prewitt, P.D. and Allen, J.E., "The Double Sheath Associated with a Hot Cathode," Proceedings of the Royal Society of London, Ser. A, Vol. 348, No. 1655, April 1976, pp. 435 446.

${ }^{17}$ Rapp, D. and Englander-Golden, P., "Total Cross Sections for Ionization and Attachment in Gases by Electron Impact: I. Positive Ionization,” The Journal of Chemical Physics, Vol. 43, No. 5, Sept. 1, 1965, pp. 1464-1479.

${ }^{18}$ Brode, R.R., "The Quantitative Study of the Collisions of Electrons with Atoms," Review of Modern Physics, Vol. 5, Oct. 1933, pp. 257-279.

${ }^{19}$ Hayashi, M., "Determination of Electron-Xenon Total Excitation Cross-Sections, from Threshold to 100-eV, from Experimental Values of Townsend's $\alpha$," Journal of Physics D: Applied Physics, Vol. 16, 1983, pp. 581-589. 


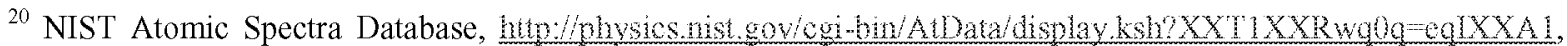
accessed July 3, 2002.

${ }^{21}$ Gombosi, T., Gaskinetic Theory, Cambridge University Press, Cambridge, Great Britain, 1994.

22 Domonkos, M.T., Williams, G.J., Gallimore, A.D., and Patterson, M.J., "Low-Current Hollow Cathode Evaluation," AIAA Paper No. 99-2575, 35th AIAA/ASME/SAE/ASEE Joint Propulsion Conference and Exhibit, June 20-24, 1999, Los Angeles, CA.

${ }^{23}$ Striganov, A.R. and Sventitskii, N.S., Tables of Spectral Lines of Neutral and Ionized Atoms, IFI/Plenum Data Corporation, New York, 1968.

${ }^{24}$ Patterson, M.J., Verhey, T.R., Soulas, G., and Zakany, J., "Space Station Cathode Design, Performance, and Operating Specifications," IEPC Paper No. 97-170, $25^{\text {th }}$ International Electric Propulsion Conference, Aug. 24 28, 1997, Cleveland, $\mathrm{OH}$ 


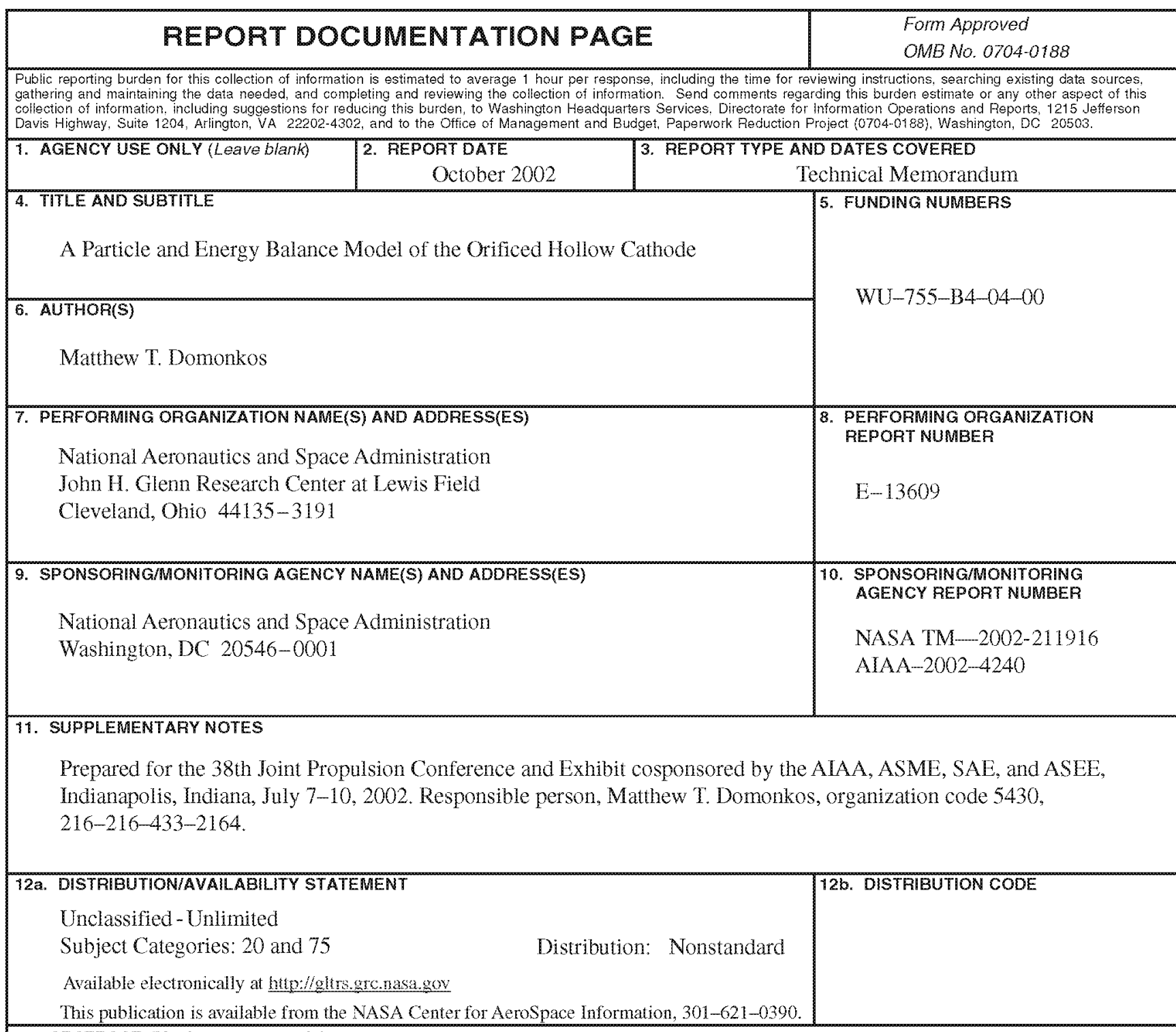

13. ABSTRACT (Maximum 200 words)

A particle and energy balance model of orificed hollow cathodes was developed to assist in cathode design. The model presented here is an ensemble of original work by the author and previous work by others. The processes in the orifice region are considered to be one of the primary drivers in determining cathode performance, since the current density was greatest in this volume (up to $1.6 \times 10^{8} \mathrm{~A} / \mathrm{m}^{2}$ ). The orifice model contains comparatively few free parameters, and its results are used to bound the free parameters for the insert model. Next, the insert region model is presented. The sensitivity of the results to the free parameters is assessed, and variation of the free parameters in the orifice dominates the calculated power consumption and plasma properties. The model predictions are compared to data from a low-current orificed hollow cathode. The predicted power consumption exceeds the experimental results. Estimates of the plasma properties in the insert region overlap Langmuir probe data, and the predicted orifice plasma suggests the presence of one or more double layers. Finally, the model is used to examine the operation of higher current cathodes.

\section{SUBJECT TERMS}

Hollow cathode; Ion thruster; Hall thruster; Plasma

15. NUMBER OF PAGES

26

16. PRICE CODE

\begin{tabular}{|c|c|}
\hline $\begin{array}{l}\text { 17. SECURITY CLASSIFICATION } \\
\text { OF REPORT }\end{array}$ & $\begin{array}{l}\text { 18. SECURITY CLASSIFICATION } \\
\text { OF THIS PAGE }\end{array}$ \\
\hline Unclassified & Unclassified \\
\hline
\end{tabular}

NSN 7540-01-280-5500
19. SECURITY CLASSIFICATION OF ABSTRACT

Unclassified

\section{LIMITATION OF ABSTRACT}

